\title{
A AÇÃo CIVIL PÚBLICA A PARTIR dO ORDENAMENTO JURÍDICO BRASILEIRO COMO INSTRUMENTO DE CONTROLE DOS ATOS CORRUPTIVOS: UM ENFOQUE ACERCA DA ATUAÇÃO DOS SEUS LEGITIMADOS ATRAVÉS DAS DECISÕES DO TJ/RS ${ }^{1}$
}

\author{
Eduarda Simonetti Pase $e^{2}$ \\ Caroline Müller Bitencourt ${ }^{3}$
}

\section{RESUMO}

O presente estudo tem por objetivo apresentar o instituto da Ação Civil Pública prevista no artigo 129, inciso III da Constituição Federal de 1988 no Brasil, e regulamentada pela Lei ${ }^{\circ}$ $7.347 / 85$, demonstrando a sua utilização na propositura de ações que visem coibir atos corruptivos que venham a ferir o Patrimônio Público incidindo assim nos interesses da sociedade, por meio de todos os seus legitimados. Para tanto, preliminarmente, faz-se uma análise dos objetivos da lei, seu objeto e conteúdo, sempre indicando o posicionamento dos Tribunais Superiores e da doutrina pátria. Em uma análise prática da sua utilização, tomam-se por base as decisões proferidas pelo Tribunal de Justiça do Estado do Rio Grande do Sul para, ao final, realizar uma análise quantitativa da incidência de Ações Civis Públicas como instrumento processual (in) hábil na prevenção, controle e, sobretudo, no enfrentamento à corrupção. Outrossim, faz-se um estudo acerca da predominância de Ações Civis Públicas propostas pelo Ministério Público, desproporcionalmente ao número de ações intentadas pelos demais legitimados. Conclui-se que a Ação Civil Pública, embora embrionariamente não tenha previsto a possibilidade do seu manejo para coibir práticas corruptas, tem-se destacado como instrumento largamente utilizado para este propósito.

Palavras-chave: Ação Civil Pública. Corrupção. Improbidade Administrativa. Ministério Público. Legitimados.

\begin{abstract}
This study aims to present the Institute of Public Civil Action under Article 129, paragraph III of the 1988 Constitution in Brazil and regulated by Law n. 7.347/85, demonstrating their use in the bringing of actions aimed at preventing acts corruptive that may hurt the Public Property thus focusing on the interests of society, through all its legitimate. Preliminarily, we started with an analysis of the Law objectives, its purpose and content, always indicating the position of the High Courts and the homeland doctrine. In a practical analysis of their use, taking as a basis the judgment given by the Court of the Rio Grande do Sul State, to the end, perform a quantitative analysis of the impact of civil class actions as a procedural instrument (in) skilled in prevention, control and, especially, in addressing corruption. Moreover, it is a study on the prevalence of public civil actions filed by the Public Ministry, disproportionately to the number of shares brought by the other legitimate. We conclude that the Public Civil
\end{abstract}

\footnotetext{
${ }^{1}$ Este artigo é fruto dos debates "Projeto Interinstitucional de redes de grupos de pesquisa sobre o tema Patologias Corruptivas nas relações entre Estado, Administração Pública e Sociedade: Causas, Consequências e Tratamentos", coordenado pelo Professor Dr. Rogério Gesta Leal, como trabalho referente à bolsa de iniciação científica do CNPq, sob a orientação da Professora Dra. Caroline Müller Bitencourt.

${ }^{2}$ Aluna do Curso de Direito da Universidade de Santa Cruz do Sul - UNISC. E-mail: eduarda.pase@gmail.com.

${ }^{3}$ Doutora em Direito. Professora do Departamento de Direito na Universidade de Santa Cruz do Sul. E-mail: caroline.mb@terra.com.br.
} 
Action, though, embryonic has not provided the possibility of its management to curb corrupt practices, has been highlighted as a widely used tool for this purpose.

Keywords: Public Civil Action. Corruption. Administrative Misconduct. Public Ministry. Authenticity.

\section{INTRODUÇÃO}

A efetividade da prestação jurisdicional por meio da tutela coletiva, desde a criação da Lei $\mathrm{n}^{\mathrm{o}}$ 7.347/85, quando foi então possibilitada no Ordenamento Jurídico do Brasil a oportunidade do ajuizamento da Ação Civil Pública para proteção de certos interesses difusos e direitos coletivos, passando pela sua constitucionalização, com a expressa previsão da utilização desse instrumento processual pelo Ministério Público (CF/88, art. 129, III), tem alcançado gradativa e constante importância e amplitude.

Não obstante, em uma sociedade moderna e cada vez mais complexa, com um intrincado desenvolvimento das relações econômicas e sociais, aparecem situações nas quais determinadas atividades podem causar prejuízos ou lesões aos interesses de um grande número de pessoas, fazendo irromper adversidades desconhecidas às lides individuais. Daí se decorre a necessidade do aperfeiçoamento dos institutos legais para também tutelarem com eficiência nas situações até então desconhecidas e não reguladas.

Sendo assim, a certeza da essencialidade desse tipo de ação não se dá apenas pelo objeto da tutela coletiva. De fato, este objeto é mais amplo, pois passa por interesses difusos, direitos coletivos, individuais homogêneos e, sobretudo, por patrimônio público, o que indica a importante função conferida a essa espécie de tutela na prestação jurisdicional obtida através desse meio.

Esse destaque é resultado da ampla previsão de legitimados ativos para o manejo das ações de caráter coletivo, conforme se depreende do expresso no artigo $5^{\circ}$ da Lei $n^{\circ} 7.347 / 85$. Neste sentido, a viabilidade da utilização pelo Ministério Público, pela Defensoria Pública e pelos entes federativos e associativos já indica, por si só, o alcance dos efeitos ali conferidos pelo Poder Judiciário.

Assim, o presente estudo visa demonstrar o manejo da Ação Civil Pública como instrumento (in) hábil utilizado, sobretudo pelo Ministério Público, para o enfrentamento de condutas corruptas que venham a ferir o patrimônio público. Num primeiro momento, procura-se evidenciar questões atinentes a lei propriamente dita, fazendo-se uma leitura do seu objeto juntamente com a especificação do mesmo e a sua extensão dada pelos agentes 
propositores de Ações Civis Públicas para ato de corrupção (valendo-se assim de uma leitura lato sensu da corrupção, sem especificar condutas ou tipificações tomando-se, como exemplo, os atos de improbidade administrativa). Desde já, indica-se a defesa da jurisprudência do seu cabimento para demandas não apenas condenatórias, mas também demandas com pedidos constitutivos ou desconstitutivos de atos ou direitos.

Num segundo ponto, partindo-se das posições jurisprudenciais, procura-se demonstrar a equiparação do instituto da Ação Civil Pública para com a Ação Civil prevista na Lei ${ }^{\circ}$ 8.429/92 pela jurisprudência, mesmo que ambos os institutos guardem importantes distinções.

Por fim, faz-se uma análise metodológica das decisões em Ações Civis Públicas a partir da jurisprudência do Tribunal de Justiça do Estado do Rio Grade do Sul, com o desígnio de investigar a incidência de Ações Civis Públicas que tenham por objeto alguma ação ensejadora de ato de corrupção, bem como a de demonstrar a disparidade de ações promovidas pelo Ministério Público e pelos demais legitimados no que tange a este objeto.

O estudo não possui a pretensão de esgotar o tema, mas apenas contribuir com considerações e dúvidas que mereçam ser abordadas e discutidas frente à existência de consideráveis controvérsias doutrinárias e jurisprudenciais que ainda as cercam, de modo a aprimorar a utilização das ações coletivas, em especial a Ação Civil Pública, no que se refere à limitação de manejo do seu próprio objeto.

\section{O INSTITUTO DA AÇÃo CIVIL PÚBlicA NO BRASIL: NOÇÕES PRELIMINARES}

O direito de acesso à justiça é a possibilidade do indivíduo ter a admissão a um processo efetivo com os meios e recursos a ele inerentes, de modo a obter um justo provimento jurisdicional.

No que se refere à expressão "acesso à justiça", importa destacar que há duas formas de interpretação para fins de se alcançar uma definição conceitual, dentre elas, a definição material e a definição formal.

Neste sentido, segundo Mauro Cappelletti e Bryant Garth (2002, p. 8), conforme o estudo das ondas renovatórias de acesso à justiça, a expressão em foco serve para determinar duas finalidades básicas do sistema jurídico [...]. Em primeiro lugar, o sistema deve ser

\footnotetext{
${ }^{4} \mathrm{O}$ fundamento constitucional para o princípio do acesso à justiça pode ser sentido no art. $5^{\circ}$, inciso XXXV da CRFB/88, o qual prescreve que "a lei não excluirá da apreciação do Poder Judiciário lesão ou ameaça a direito".
} 
igualmente acessível a todos; já em segundo lugar, ele deve produzir resultados que sejam individual e socialmente justos.

Nesta percepção, Nadja Azevedo Silva ensina que

as transformaçães sociais, a evolução da sociedade, bem como a globalização são
fatores importantes que contribuem para o estudo jurídico de forma a tê-la sempre
atualizada. Assim, diante da necessidade da coletividade em ter seus direitos
resguardados fez surgir no ordenamento jurídico diversas leis facilitando o acesso à
justiça e obtenção da tutela jurisdicional, principalmente quanto aos direitos de
terceira geração. (SILVA, 2012, p. 4)

Não obstante, com a compreensão da necessidade de se garantir tutela às crescentes demandas coletivas, surgiram no ordenamento jurídico pátrio variados instrumentos tendentes a tutelar os direitos difusos e coletivos, dentre eles a Ação Popular, o Mandado de Segurança coletivo e a Ação Civil Pública.

Neste linear, a Ação Civil Pública tem sua previsibilidade constitucional sob o fundamento de que todos têm acesso à justiça para a proteção de direitos subjetivos ou da comunidade, tendo como escopo a atuação da função jurisdicional do Estado. Tanto é verdade que a norma constitucional tem por objetivo tutelar interesses essenciais da comunidade, pois em razão da inércia do Poder Judiciário, indispensável à sua atuação imparcial, importante é saber quem está legitimado a defender tais interesses, os quais não podem subordinar-se à livre disposição de seus titulares.

Prevista, portanto, na Constituição Federal de 1988, em seu artigo 129, III, a Ação Civil Pública é regulada pela Lei no 7.347/85 e também tratada em demais dispositivos legais esparsos, como por exemplo, o Código de Defesa do Consumidor ${ }^{5}$. Antes da promulgação da Constituição de 1988, não se utilizava o instituto da Ação Civil Pública para defender interesses diversos dos que expressamente estavam previstos na lei que a disciplina. Entrementes, com a chegada da Constituição de 1988, outros direitos coletivos e difusos puderam ser tutelados por este instituto. Segundo Carvalho (2004),

antes da vigente Constituição, não se cogitou, com profundidade, do emprego da ação civil pública para defesa de outros direitos coletivos senão aqueles que a lei enunciava: meio ambiente, consumidor e patrimônio artístico, estético, histórico, turístico e paisagístico. Com a extensão do instrumento para outros direitos coletivos e difusos, passou o legislador, sem perda de tempo, a proteger interesses diversos daqueles que a Lei $\mathrm{n}^{\circ}$ 7.347/85 mencionava. (CARVALHO FILHO, 2004, p. 10 , grifo do autor)

\footnotetext{
${ }^{5}$ Lei $\mathrm{n}^{\circ} 8.078 / 90$, art. 81 .
} 
Portanto, o objeto geral da Ação Civil Pública é a tutela aos interesses difusos ou coletivos - proveito jurídico que o autor vai lograr no caso de acolhimento da sua demanda. Destaca ainda o citado autor que,

no que tange à ação civil pública, vimos que a providência alvitrada pelo autor é de conteúdo condenatório, seja para condenar o réu a pagamento em dinheiro, seja para obriga-lo ao cumprimento de obrigação de fazer ou não fazer. (CARVALHO FILHO, 2004, p. 88-89, grifo do autor)

A Ação Civil é aquela que tem por objeto um litígio civil. É ação não penal e pública por seu conteúdo, porque objetiva tutelar interesses difusos ou coletivos. Se toda a Ação Civil, mediatamente, busca a consecução do interesse público no âmbito processual civil, seu objetivo imediato é, em geral, a inferência de uma pretensão menor, isto é, particular/individual. Entretanto, quando a própria pretensão originadora da lide advém de interesses difusos ou coletivos, está-se diante da Ação Civil Pública.

Neste sentido, adverte Carlos Santos que a:

[...] Ação Civil Pública, no caso da improbidade administrativa, é a ação civil de interesse público imediato, ou seja, a utilização do processo civil como um instrumento para a proteção de um bem, cuja preservação interessa à toda coletividade (SANTOS, 2014).

Na mesma linha de pensamento, Carvalho Filho elucida que:

na expressão ação civil pública não se identifica a pretensão que lhe constituiu o objeto. $\mathrm{O}$ adjetivo civil indica meramente que ação tem natureza não-penal, não se voltando, portanto, a pedidos condenatórios decorrentes da prática de ilícitos penais. Já o adjetivo pública deve ser visto como antagônico à ação privada, de como a indicar que a ação pode ser deflagrada por órgão do próprio Estado, como é o caso especial do Ministério Público, na defesa de interesses de natureza coletiva e com vistas ao bem-estar da comunidade, ao contrário da ação, de sentido clássico, só permitida, em regra, ao indivíduo que fosse realmente o titular do direito a ser tutelado. Poder-se-á, pois, afirmar que se trata de ação pública porque não se cinge à esfera dos interesses singulares, consagrada pela doutrina individualista das ações, mas, ao contrário, visa a alcançar interesses grupais da sociedade (...). (CARVALHO FILHO, 2004, p. 2-3, grifo do autor)

Contudo, o desenvolvimento jurídico-formal de instrumento desse tipo especial de ação pode, proporcionar o alargamento desse objeto imediato em ordem a alcançar outra modalidade, muito embora tendo como propósito sempre os interesses difusos e coletivos a serem tutelados no processo.

A exemplo da ampliação do objeto pode-se citar a defesa do patrimônio público e da moralidade administrativa que no dizer do autor acima referido, ${ }^{6}$

\footnotetext{
${ }^{6}$ No dia 25/06/2014 foi publicada a Lei $\mathrm{n}^{\mathrm{o}}$ 13.004/2014 que inclui expressamente como objeto a ser tutelado pela via da Ação Civil Pública o patrimônio público e social, já previsto na Constituição Federal. Esta lei alterou os
} 
[...] outra ampliação do objeto ocorreu com a Lei $n^{\circ}$ 8.625, de 12/2/1993 - a Lei Orgânica do Ministério Público. Com efeito, ao dispor sobre as funções gerais do Ministério Público, além das demais constantes nas Constituições e nas leis, estabeleceu o estatuto no art. 25, IV, caber ao órgão o ajuizamento de ação civil pública: a)Para a proteção, prevenção e reparação dos danos causados ao meio ambiente, ao consumidor, aos bens e direitos de valor artístico, estético, histórico, turístico e paisagístico, e a outros interesses difusos, coletivos e individuais indisponíveis e homogêneos; b)Para a anulação ou declaração de nulidade de atos lesivos ao patrimônio público ou à moralidade administrativa do Estado ou de Município, de suas administrações indiretas ou fundacionais ou de entidades privadas de que participem. (CARVALHO FILHO, 2004, p. 92, grifo do autor)

É neste terreno que o presente trabalho se debruça, isto é, busca-se apresentar o alargamento do objeto da Ação Civil Pública, sobretudo pelo Ministério Público, maneando-a como meio (in) hábil a ser utilizado no tratamento de atos corruptivos, no que tange a improbidade administrativa (dado que estes afetam o patrimônio público), sob o argumento de que a probidade administrativa é consectária da moralidade administrativa, que por sua vez é anseio popular e, portanto, interesse difuso.

Entretanto, entende-se que a Ação Civil Pública não é de toda sorte o instrumento adequado para a repressão dos atos de improbidade administrativa que venham a configurar condutas corruptivas, como se observará no resultado da pesquisa jurisprudencial. Ademais, é bem verdade que o artigo 17 da Lei de Improbidade Administrativa traz o órgão do Ministério Público como o titular da ação por ato de improbidade administrativa ${ }^{7}$. Isto, pois, a Ação Civil Pública guarda discrepante relação para com a Ação Civil prevista na Lei nº 8.429/92, embora no final atinjam resultados semelhantes, reservados as peculiaridades de cada procedimento.

\section{A AÇÃO CIVIL PÚbliCA COMO INSTRUMENTO DE CONTROLE DOS ATOS CORRUPTIVOS}

A Lei no 7.347/85 prevê em seu artigo $5^{\circ}$ os legitimados para proporem a Ação Civil Pública. Dentre eles, destacam-se o Ministério Público, a Defensoria Pública ${ }^{8}$, a União, Estados, Distrito Federal e Municípios e as Associações que estejam constituídas há pelo

$\operatorname{artigos} 1^{\circ}, 4^{\circ}$ e $5^{\circ}$ da Lei $n^{\circ} 7.347 / 85$. Ela teve um período de vacatio legis de 60 (sessenta) dias contados da sua publicação oficial.

${ }^{7}$ É necessário que se explique o motivo pelo qual se usa a expressão "improbidade administrativa" para se referir à corrupção. A jurisprudência trata como "corrupção", os crimes de corrupção ativa e passiva, condutas descritas nos artigos 333 e 317, respectivamente do Código Penal. Por "improbidade administrativa" a jurisprudência remete às condutas descritas nos artigos $9^{\circ}, 10$ e 11 da Lei $n^{\circ} 9.429 / 92$, que são as condutas objeto de discussão do estudo.

${ }^{8}$ A legitimidade ativa da Defensoria Pública para propor Ação Civil Pública, foi concedida pela lei $\mathrm{n}^{\circ}$. 11.448/2007 que alterou a redação do art. $5^{\circ}$, inciso II da Lei ${ }^{\circ}$. $7.347 / 85$, inserindo a Defensoria no rol de legitimados. 
menos um ano e que incluam, entre as suas finalidades institucionais, a proteção ao meio ambiente, ao consumidor, à ordem econômica, à livre concorrência, aos direitos de grupos raciais, étnicos ou religiosos ou ao patrimônio artístico, estético, histórico, turístico e paisagístico.

Diante da classificação de que as leis são materiais ou formais, é possível afirmar que a Lei $\mathrm{n}^{\circ} 7.347 / 85$ é de natureza eminentemente formal, uma vez que se destina a regular a ação protetiva dos vários direitos subjetivos e deveres jurídicos atinentes ao meio ambiente, ao consumidor e a outros interesses coletivos e difusos. Em verdade, só eventualmente a lei exibe normas de direito material (CARVALHO FILHO, 2004, p. 2) ${ }^{9}$.

Alerta o referido autor que:

A pretensão na ação civil pública não tem, assim, relação direta com sua terminologia e consiste na tutela de direitos coletivos e difusos, como consta em seu art. $1^{\circ}[\ldots]$. Aliás, a desconexão entre a terminologia e o objeto da ação se mostra mais nítida nos termos do art. 129, III, da Constituição Federal, que comete ao Ministério Público a função de promover o inquérito civil e a ação civil pública, para a proteção do patrimônio público e social, do meio ambiente e de outros interesses difusos e coletivos (CARVALHO FILHO, 2004, p. 3, grifo do autor).

Tanto é assim que a qualificação da Ação Civil Pública, como é possível observar, mantém relação com outros elementos e não apenas com o pedido postulado por aqueles que são legitimados à sua propositura.

Dessa forma, tem sido prática recorrente nos tribunais do país o entendimento de que a Ação Civil Pública é também instrumento processual adequado conferido não apenas ao Ministério Público, mas também aos demais co-legitimados para o exercício do controle popular sobre os atos dos poderes públicos, exigindo tanto a reparação do dano causado ao patrimônio público por ato corruptivo, quanto à aplicação das sanções previstas no artigo 37, parágrafo $4^{\circ}$ da Constituição Federal de 1988, estipuladas ao agente público, em decorrência de sua irregular conduta ${ }^{10}$.

\footnotetext{
${ }^{9}$ É o caso, v.g., do art. $6^{\circ}$, que assegura a qualquer pessoa o direito de provocar a iniciativa do Ministério Público, com informações sobre a violação dos interesses tutelados; ou do art. 10, que prevê tipo penal.

${ }^{10}$ Tanto é assim que o entendimento do Superior Tribunal de Justiça aduz no seguinte sentido, como se depreende do seguinte julgado: ADMINISTRATIVO. RECURSO ESPECIAL. AÇÃO CIVIL PÚBLICA SOB A IMPUTAÇÃODE ATO DE IMPROBIDADE ADMINISTRATIVA. AS DISPOSIÇÕES DA LEI 8.429/92SÃO APLICÁVEIS AO PARTICULAR QUE, EM TESE, INDUZA OU CONCORRA PARA APRÁTICA DO ATO DE IMPROBIDADE OU DELE SE BENEFICIE SOB QUALQUERFORMA DIRETA OU INDIRETA. O MINISTÉRIO PÚBLICO POSSUI LEGITIMIDADE ATIVA PARA A PROPOSITURA DA AÇÃO CIVIL PÚBLICA POR ATO DEIMPROBIDADE. EXIGÊNCIA DA DEMONSTRAÇÃO DA JUSTA CAUSA PARA O RECEBIMENTO DA PETIÇÃO INICIAL. RECURSO ESPECIAL PROVIDO. (...) 2. O Ministério Público tem legitimidade ad causam para a propositura de ação civil pública objetivando o ressarcimento de danos ao erário, decorrentes de atos de improbidade (AgRg no AREsp.76.985/MS, Rel. Min. CESAR ASFOR ROCHA, DJe 18.5.2012). 3. As ações judiciais fundadas em dispositivos legais insertos no domínio do Direito Sancionador, o ramo do Direito Público que formula os princípios, as normas e as regras de aplicação na atividade estatal punitiva de crimes e de outros ilícitos, devem observar um rito que lhe é peculiar, o
} 
Costa aduz que, segundo posição doutrinária e jurisprudencial, a Ação Civil Pública intentada pelo Ministério Público não deve ser utilizada tão somente para o ressarcimento de danos ao erário, uma vez que isso não se amolda suficientemente às suas finalidades sociais (COSTA, 2011).

Não obstante, o autor refere ainda que a alternatividade que o dispositivo enseja não impede a cumulação, numa mesma ação, dos pedidos de prestar ou não algum fato e de indenizar em certa quantia de dinheiro.

Corroborando com este pensar, Vigliar entende que:

\begin{abstract}
defender o patrimônio público é defender a um só tempo: interesse social (catalogado indubitavelmente na categoria de interesses difusos, abraçados pela nova ordem constitucional) e a própria ordem jurídica, já que está prevista a possibilidade de defesa do patrimônio público não só pelo Ministério Público, na defesa dos interesses transindividuais, como também para o próprio cidadão, mediante ação popular. (VIGLIAR, 1999, p. 154).
\end{abstract}

Nesta esteira, o artigo $3^{\circ}$ da Lei $n^{\circ} 7.347 / 85$ preconiza que o objeto da ação em tela é a condenação em dinheiro ou o cumprimento de obrigação de fazer ou não fazer, estando subentendidos seus reais objetivos que são os de prevenção, reparação e ressarcimento dos danos causados aos interesses transindividuais.

Desta forma, verifica-se que o viés preventivo possui uma inegável dimensão social mais significativa, sendo os demais meramente subsidiários, considerando-se que a reparação do dano apenas aparecerá como objetivo da lei quando o aparato preventivo se mostrar suficiente. Por sua vez, o aspecto ressarcitóriona visão de Soares, "apresenta-se como o último objetivo da lei em destaque, só cabendo falar em indenização quando a função preventiva tenha sido ineficaz e o dano, a lesão venha a ser considerado irreparável". (SOARES, 2012, p. 2).

Assim também se depreende das lições de Marcelo Alexandrino e Vicente Paulo, quando afirmam que:

\footnotetext{
a ação civil pública visa a apurar responsabilidade por danos morais ou patrimoniais causados aos bens jurídicos por ela tutelados. Mais precisamente, a ação pode ter finalidade preventiva ou repressiva, isto é, pode ter por escopo evitar uma lesão, ou, se já ocorrida, repará-la (se possível) e responsabilizar os que a ocasionaram, por ação ou omissão. (ALEXANDRINO; PAULO, 2012, p.912).
}

qual prevê, tratando-se de ação de imputação de ato de improbidade administrativa, a exigência de que a petição inicial, além das formalidades previstas no art. 282 do CPC, deva ser instruída com documentos ou justificação que contenham indícios suficientes da existência do ato de improbidade (art. 17, § $6^{\circ}$. da Lei 8.429/92), sendo certo que ação temerária, que não convença o Magistrado da existência do ato de improbidade ou da procedência do pedido, deverá ser rejeitada (art. 17, § $8^{\circ}$ da Lei 8.429/92). (...). (STJ - REsp: 952351 RJ 2007/0113128-6, Relator: Ministro NAPOLEÃO NUNES MAIA FILHO, Data de Julgamento: 04/10/2012, T1 PRIMEIRA TURMA, Data de Publicação: DJe 22/10/2012). 
É importante ressaltar que a hierarquia que existe entre os objetivos acima citados não impossibilita que coexistam em certa situação concreta. A exemplo disso, na esfera cível, o Ministério Público poderá operar a Ação Civil Pública para diversas finalidades sem, contudo, confrontar ou ferir os seus objetivos e princípios. Isto é, o Ministério Público pode, por exemplo, promover na mesma Ação Civil Pública pedidos com finalidades diversas, isto é, condenatórias, constitutivas ou desconstitutivas, sempre que estiver em discussão o interesse público e social, de acordo com o objeto de competência da Ação Civil Pública ${ }^{11}$.

Corroborando para este entendimento, Carvalho Filho ilustra dizendo que:

exemplo interessante [...] deu-se no Estado do Rio de Janeiro em outubro de 1994. Tendo o Governador do Estado produzido ato de nomeação de certo Deputado para o cargo de Conselheiro do Tribunal de Contas do Estado, embora não preenchesse o nomeado o requisito da moralidade administrativa necessário para ocupa-lo por força de diversos fatos a ele imputados e que estavam sendo apreciados em outras ações, o Ministério Público, através de seu Procurador-Geral de Justiça, ajuizou ação civil pública não somente para obter providência judicial visando a impedir a posse do nomeado (pedido de conteúdo condenatório), como também para anular o ato de nomeação por vício em seu motivo (pedido de conteúdo constitutivo). O pedido só foi juridicamente possível pelo fato de ser a moralidade administrativa o interesse difuso a ser protegido. (CARVALHO FILHO, 2004. p. 92). (Grifos no original).

Prepondera ainda o Ministro Luiz Fux, em passagem da ementa no REsp $n^{\circ}$ 510.150/MA, que:

[...] Torna-se, pois, indiscutível a adequação dos pedidos de aplicação das sanções previstas para ato de improbidade à ação civil pública, que se constitui nada mais do que uma mera denominação de ações coletivas, às quais por igual tendem à defesa de interesses meta-individuais. (FUX, 2004, D.J. 29/03/2004, p. 173) ${ }^{12}$.

Portanto, esse entendimento explica os resultados obtidos e demonstrados a seguir. Não se pode contrariar que o manejo da Ação Civil Pública vai além da simples proteção dos bens descritos no arcabouço do artigo $1^{\circ}$ da Lei $n^{\circ} 7.347 / 85$. Ela tem sido uma das vias processuais utilizadas para a proteção do patrimônio público, dos princípios constitucionais da administração pública e para a coibição de atos de improbidade administrativa ou

${ }^{11}$ Nesse sentido também, passagem da ementa do RESP nº 749988/SP, de relatoria do Ministro Luiz Fux, publicado no D.J em 08/08/2006: "PROCESUAL CIVL. RECURSO ESPECIAL. AÇÃO CIVL PÚBLICA. ATO DE IMPROBIDAE. CAPCIDAE POSTULATÓRIA. ARTIGO 25, IV, "B”, DA LEI 8.625/93. LEGITMATIO AD CAUSAM DO PARQUET. ARTS. 127 E129 DA CF/8. PATRIMÔNIO PÚBLICO. DEVR DE PROTEÇÃO. (...) omissis. 9. Outrossim, impõe-se, ressaltar que o artigo 25, IV, "b, da Lei 8.625/93 permite ao Ministério Público ingressar em juízo, por meio da propositura dação civil pública para anulação ou declaração de nulidade de atos lesivos ao patrimônio público ou à moralidade administrativa do Estado ou de Município, de suas administrações indiretas ou fundacionais ou de entidades privadas deque participem. 10. Deveras, o Ministério Público, ao propor ação civil pública por ato de improbidade, visa a realização do interesse público primário, protegendo o patrimônio público, com a cobrança do devido ressarcimento dos prejuízos causados ao erário municipal, o que configura função institucional/típica do ente ministerial, a despeito de tratarse de legitimação extraordinária”. (RESP nº 749988/SP, de relatoria do Ministro Luiz Fux, publicado no D.J em 08/08/2006). 
simplesmente atos lesivos, ilegais ou imorais, conforme prevê o texto do art. 12 da Lei 8.429/92 (de acordo com o art. 37, $\S 4^{\circ}$, da Constituição Federal e art. $3^{\circ}$ da Lei n. ${ }^{\circ}$ 7.347/85).

\section{A AÇÃO CIVIL PÚbliCA E SUA INCIDÊNCIA EM CAUSAS REFERENTES ÀIMPROBIDADE ADMINISTRATIVA NA JURISPRUDÊNCIA DO TJ/RS: UMA ABORDAGEM QUANTITATIVA}

Como já referido anteriormente, o presente artigo partiu da problemática acerca da utilização da Ação Civil Pública como instrumento processual (in) hábil manejado no enfrentamento de atos corruptivos. Demonstrou-se que os Tribunais Superiores têm admitido o seu uso para o enfrentamento de questões atinentes a improbidade administrativa, equiparando a Ação Civil Pública com o procedimento previsto na Lei nº 8.429/92.

Partindo-se deste pressuposto, tratou-se de investigar na jurisprudência do Tribunal de Justiça do Estado do Rio Grande do Sul qual era a incidência de Ações Civis Públicas com tal objeto. Elegeu-se este tribunal como fonte de pesquisa por ser o de maior proximidade e, sobretudo, pelo relevante trabalho que historicamente tem feito através de sua reconhecida atuação a nível regional e nacional em questões deste viés.

Para a análise de seus julgados, algumas raias utilizadas necessitam ser mencionadas e explicadas a fim de indicar e clarear a metodologia de pesquisa e análise, isto é, demonstrar o padrão de busca que resultou nos documentos que serão citados e analisados numericamente. Há ainda que se salientar a existência de limites de investigação de um estudo empírico, sobretudo perante a impossibilidade de exaurimento dos julgados.

Neste contexto, a pesquisa realizada adotou como lapso temporal padrão o período de 04 de agosto de 2013 até 04 de agosto de 2014, considerando-se a data de publicação no site do Tribunal de Justiça do Rio Grande do Sul, valendo-se dos recursos pesquisa de jurisprudência e busca avançada.

Sendo assim, ilustradamente, o preenchimento dos campos para a pesquisa quantitativa da área de busca avançada se deu da seguinte forma: Tribunal: Tribunal de Justiça do RS; Órgão Julgador: Todos; Relator: Todos; Ementa $^{13}$; Seção: Cível $^{14}$; Tipo de

\footnotetext{
${ }^{13}$ Porque ao selecionar também, inteiro teor, o filtro buscaria todos os documentos que houvesse as palavras e expressões utilizadas de forma esparsa.

${ }^{14}$ Porque o filtro do TJ/RS ao selecionar também a seção crime reporta para os crimes de corrupção ativa e passiva, os quais não são objeto do presente estudo. Por isso da utilização da expressão improbidade administrativa como sinônimo de corrupção. De outra forma, para analisar a incidência de ações civis públicas
} 
processo: $\operatorname{Todos}^{15}$; Número: Nenhum; Comarca de origem: Nenhuma; Tipo de decisão: Acórdão; Data de julgamento: Nenhuma; Data de publicação: 04/08/2013 até 04/08/2014; Procurar resultados: com todas as palavras: improbidade administrativa; com a expressão: ação civil púbica; com qualquer uma das palavras: nada; sem as palavras: nada; Classificar: por data decrescente.

O filtro encontrou 233 acórdãos, isto é, quantitativamente a pesquisa encontrou 233 acórdãos, sendo ainda necessária a leitura de cada julgado, uma vez que pode ocorrer a repetição de uma ementa e a desconsideração de todo o documento. Destes 233 documentos, foram analisados 100, visando estabelecer parâmetros de maior controle sobre os números e dados trazidos pela busca. Os resultados obtidos foram: 90 acórdãos eram de Ações Civis Públicas por ato de improbidade administrativa propostas pelo Ministério Público. Três acórdãos eram de Ações Civis Públicas intentas pelo Estado do Rio Grande do Sul, sendo que em uma delas o autor foi o Departamento Autônomo de Estradas de Rodagem do RS DAER/RS, as quais também tinham por objeto atos de improbidade administrativa. Três ações se repetiam. E 4 documentos tinham por objeto condutas corruptivas, mas não eram ações civis públicas e, sim, ações civis por ato de corrupção.

É necessário esclarecer que a pesquisa não entrou no mérito dos acórdãos. Ou seja, dentre essas ações não foram analisadas quais delas houve a condenação e confirmação da existência da conduta corruptiva, o que, significa dizer que mesmo tratando-se de atos ímprobos, podem não ter configurado os mesmos, pela absolvição.

Como já relatado anteriormente, não resta dúvida de que a Lei $n^{\circ}$ 8.429/92 contemplou ação própria para enfrentar a improbidade administrativa perpetuada por enriquecimento ilícito à custa da Administração, ou por condutas causadoras de danos ao erário, ou, ainda por violação a princípios administrativos (arts. $9^{\circ}$ ao 11).

No seu texto, não se encontra qualquer referência à Ação Civil Pública. A lei de improbidade limita-se a aludir duas ações: a primeira é a ação de sequestro (art. 16) processo de natureza cautelar - e a segunda não recebeu nomen juris específico, já que foi feita referência apenas à “ação principal” (art. 17). Adiante, a lei faz menção à "sentença que julgar procedente a ação civil de reparação de dano" (art. 18). Não é difícil verificar que a impropriedade técnica com que a lei indicou a via judicial idônea às tutelas nela previstas haveria mesmo de provocar hesitações em sua interpretação.

na corrupção, o filtro do TJ/RS precisa ser direcionado para as palavras improbidade administrativa, sob pena de haver direcionamento para os crimes de corrupção ativa e passiva.

${ }^{15}$ Porque ao selecionar um tipo de processo específico, o filtro não corresponde com o número real de ações, muitas vezes zerando a busca. 
Nesta feita, analisando-se o quadro normativo procedimental relativo à Ação Civil Pública regulada na Lei no 7.347/85 e à ação prevista na Lei no 8.429 , encontra-se, ao menos, um ponto comum: para ambas é o Ministério Público um dos legitimados à sua propositura. E esse talvez seja um fato do qual podem realmente emanar discrepâncias quanto à identificação das ações.

Mesmo com as diferenças visíveis, o fato é que, como demonstram os números anteriormente descritos, a jurisprudência tem aceitado o manejo da Ação Civil Pública para o enfrentamento de atos corruptivos, igualando ambas as ações. Se tal fato é prejudicial aos objetivos dos institutos, é difícil precisar. Ocorre que o enfrentamento tem surtido efeito, mesmo com um instituto processual não totalmente hábil.

\section{CONCLUSÃO}

Ainda em tempo, é necessário mais uma vez reforçar que o objetivo do estudo foi analisar a incidência da Ação Civil Pública em casos que tivessem por tema condutas corruptas. Neste trabalho, muitas vezes utilizou-se a expressão "improbidade administrativa" para se referir ao assunto. Nesse ponto, é preciso esclarecer que tal expressão foi utilizada devido ao fato de que o banco de dados em que se realizou a pesquisa cerne do estudo, qual seja, site do Tribunal de Justiça do Estado do Rio Grande do Sul, assim entende como corrupção, para diferenciar dos crimes de corrupção ativa e passiva previstos no Código Penal, valendo-se assim de uma leitura lato sensu da corrupção, sem especificar condutas ou tipificações, tomando-se, como exemplo, os atos de improbidade administrativa.

Feito esse importante esclarecimento, como já demonstrado, os institutos processuais aqui analisados guardam importantes distinções. O devido manejo do instituto da Ação Civil Pública na busca pela tutela coletiva dos interesses difusos, direitos coletivos e, sobretudo, do patrimônio público, é essencial para que se alcancem devidamente os objetivos de tal via, através de uma efetiva prestação jurisdicional.

Desta forma, ter o domínio acerca dos legitimados ativos e de suas nuances para o exercício da tutela coletiva para fins de compreender quais interesses estão sendo colocados diante do Poder Judiciário, bem como o domínio sobre os conceitos e matérias que podem ser tuteladas pela via coletiva, é de suma importância.

É neste momento que tem-se firmado entendimento na jurisprudência de que exigências formais para o exercício da defesa coletiva devem ser afastadas, para não limitar a legitimação ativa de forma imprópria a ponto de atentar ao Estado Democrático de Direito. 
O que se busca tentar demonstrar é que, embora existam as diferenças já elucidadas entre os dois institutos processuais no que tange a corrupção, tem-se admitido a concomitância de Ações Civis Públicas por ato de improbidade administrativa e Ações Civis de Improbidade Administrativa. Os resultados do levantamento jurisprudencial vão ao encontro deste fato.

Nesse sentido, a idoneidade da Ação Civil Pública, como instrumento de defesa e proteção ao patrimônio público, com manejo assegurado pelo art. 129, III, da CF, adquiriu amplitude maior do que aquela prevista na Lei $\mathrm{n}^{\circ} 7.347 / 85$, motivo pelo qual a sua propositura e a legitimidade de seus patrocinadores só devem encontrar obstáculo nos casos de evidente contrariedade ao ordenamento jurídico. Assim, admitindo-se valer de pedidos não apenas condenatórios, mas também constitutivos ou desconstitutivos de atos lesivos ao patrimônio público.

Dessa forma, importante ainda mencionar que através controle judicial, duas são as modalidades de controle que se integram no corpo da legalidade definidas pelo Estado. $\mathrm{O}$ controle da corrupção é exercido pelo Judiciário na esfera cível (quando se fala em improbidade administrativa), de acordo com o direito administrativo, e na esfera criminal, de acordo com o direito penal. Na esfera cível, a corrupção é tratada como problema administrativo do Estado, tendo em vista o problema da discricionariedade dos agentes públicos. Nessa modalidade, o Judiciário impõe à Administração Pública o ajustamento de condutas dos agentes públicos, algumas penalidades e a correção formal da finalidade administrativa.

As disputas, na dimensão do controle judicial sobre a corrupção, ocorrem pela melhor interpretação do direito e dos instrumentos formais do direito processual, de acordo com as regras de conduta do campo jurídico. A lógica da supervisão jurídica retira da política a capacidade de controle sobre as próprias delinquências, passando ao Judiciário o encargo de controlar a ação dos agentes públicos. O controle judicial da corrupção, dessa forma, pressupõe uma legalidade que indique o que é e o que não é corrupção, através de um processo conduzido na dimensão dos tribunais. E é aqui que, sobretudo, o Ministério Público tem se valido da Ação Civil Pública para buscar esse controle. O enfrentamento tem surtido efeito, mesmo que com um instituto processual não totalmente hábil. 


\section{REFERÊNCIAS}

CAPPELlETTI, M.; GARTH, B. G. Acesso à Justiça. Trad. Ellen Gracie Northfleet. Porto Alegre: Safe, 2002.

CARVAlHO FILHO, J. dos S. Ação Civil Pública. 4. ed. Rio de Janeiro: Lumen Juris, 2004.

COSTA, K. C. Ação Popular e Ação Civil Pública. Âmbito Jurídico, Rio Grande, n. 90, ano 14, jul. 2011. Disponível em: http://www.ambitojuridico.com.br/ site/?n_link=revista_artigos_leitura\&artigo_id=9888\&revista_caderno=9. Acesso em: jul. 2014.

LOUREIRO, C. M. Ação Civil Pública e o acesso à justiça. São Paulo: Método, 2004.

PAULO, V.; ALEXANDRINO, M. Direito Administrativo descomplicado. 20. ed. São Paulo: Método, 2011.

SANTOS, C. F. B. dos. A Ação Civil Pública por ato de improbidade administrativa. Associação do Ministério Público do Estado do Rio de Janeiro, Rio de Janeiro: Temas Jurídicos. Disponível em: http://www.amperj.org.br/artigos/view.asp?ID=41. Acesso em: 21 jul. 2015.

SOARES, T. de A. A atuação do Ministério Público na defesa do patrimônio público x O desenvolvimento urbano da cidade do Recife. Jus Navigandi, Teresina, n. 3270, ano 17, 14 jun. 2012. Disponível em: http://jus.com.br/artigos/22005. Acesso em: 27 jul. 2014.

VALCANOVER, F. H. Legitimidade ativa e passiva em matéria de Ação Civil Pública e Ações Coletivas. Processos Coletivos, Porto Alegre, n. 2, v. 4, 01 abr. 2013. Disponível em: http://www.processoscoletivos.net/1210-legitimidade-ativa-e-passiva-em-materia-de-acaocivil-publica-e-acoes-coletivas. Acesso em: 23 jul. 2014.

VIGLIAR, J. M. M. Ação civil pública: Lei n. 7.347 / 85 e Legislação Posterior, Ação Civil Pública Para Defesa: Meio Ambiente, Da Pessoa Portadora De Deficiência, Da Criança E Do Adolescente, Do Consumidor, Do Patrimônio Público e Combate à Improbidade Administrativa. 4. ed. São Paulo: Atlas, 1999. 